\title{
Recycling of Rare Earth Magnet Waste by Removing Rare Earth Oxide with Molten Fluoride
}

\author{
Osamu Takeda*1, Kiyotaka Nakano*2 and Yuzuru Sato \\ Department of Metallurgy, Graduate School of Engineering, Tohoku University, Sendai 980-8579, Japan
}

Recycling of rare earth magnet scrap is required for improving resource conservation. Removal of rare earth oxide from off-specification magnet alloy scrap was investigated by remelting the scrap together with fluoride flux, $\mathrm{LiF}-50 \mathrm{~mol} \% \mathrm{NdF}_{3}$ and $\mathrm{LiF}-25 \mathrm{~mol} \% \mathrm{NdF}_{3}-25 \mathrm{~mol} \%$ $\mathrm{DyF}_{3}$, at $1503 \mathrm{~K}$ for the development of novel recycling process. As a result, separation of magnet alloy from fluoride flux after remelting was fine, and neither suspension of alloy in the flux nor suspension of flux in the alloy was observed. Oxygen concentration of alloy decreased from 5000 to 160 mass-ppm by charging flux of 1.5 times of equivalent amount for complete dissolution of oxide. Substitution of neodymium in the alloy and dysprosium in the flux was observed. The investigated process should be utilized for mildly contaminated waste such as a used (endof-life) magnet because of simple process, energy saving and unlimited location. [doi:10.2320/matertrans.M-M2013836]

(Received September 22, 2013; Accepted November 5, 2013; Published January 25, 2014)

Keywords: rare earth, recycling, fluoride, deoxidation, magnet

\section{Introduction}

Neodymium (Nd)-iron (Fe)-boron (B) sintered magnet, a key device for solving environmental problems and energy problems, was developed in Japan, and the mass production was also realized. ${ }^{1)}$ At present, Japan is a major production country of the magnet in the world. However, the raw materials (rare earth oxides and rare earth metals) are imported, and the resource is scarce. Therefore, recycling of rare earth waste is required.

The major recycling process for magnet waste is based on a hydrometallurgical method. ${ }^{2)}$ The flow of recycling process is shown in Fig. 1. The magnet wastes are dissolved in acid solution such as sulfuric acid at first. Iron is precipitated to be removed by charging much alkali solution. A rare earth element isolated by using solvent extraction is precipitated as oxalates to be recovered. The oxalate is oxidized into an oxide to be a raw material of molten salt electrolysis. Rare earth metals are regenerated by using the molten salt electrolysis. Rare earth metals with trace oxygen (major impurity of magnet waste) are regenerated in the recycling process. Separation of rare earth elements is also possible. However, much waste water is generated because not only rare earth metals but also iron is dissolved by using acid solution. Furthermore, energy consumption is huge because molten salt electrolysis requires much electricity. Location for recycling operation is also limited to a country bearing a smelting facility for rare earth metals.

Many research activities are carried out in Japan in order to solve the problem of current recycling process and to develop a feasible process in Japan. ${ }^{3-12)}$ The challenges are briefly introduced in a previous article ${ }^{13)}$ although no process is put into practical use at this stage.

Based on the background, the authors developed a novel recycling process for the magnet alloy waste. The flow of the process is shown in Fig. 2. The most harmful impurity for

\footnotetext{
${ }^{* 1}$ Corresponding author, E-mail: takeda@material.tohoku.ac.jp

${ }^{* 2}$ Graduate Student, Tohoku University. Present address: SUMCO Co., Saga 849-0597, Japan
}

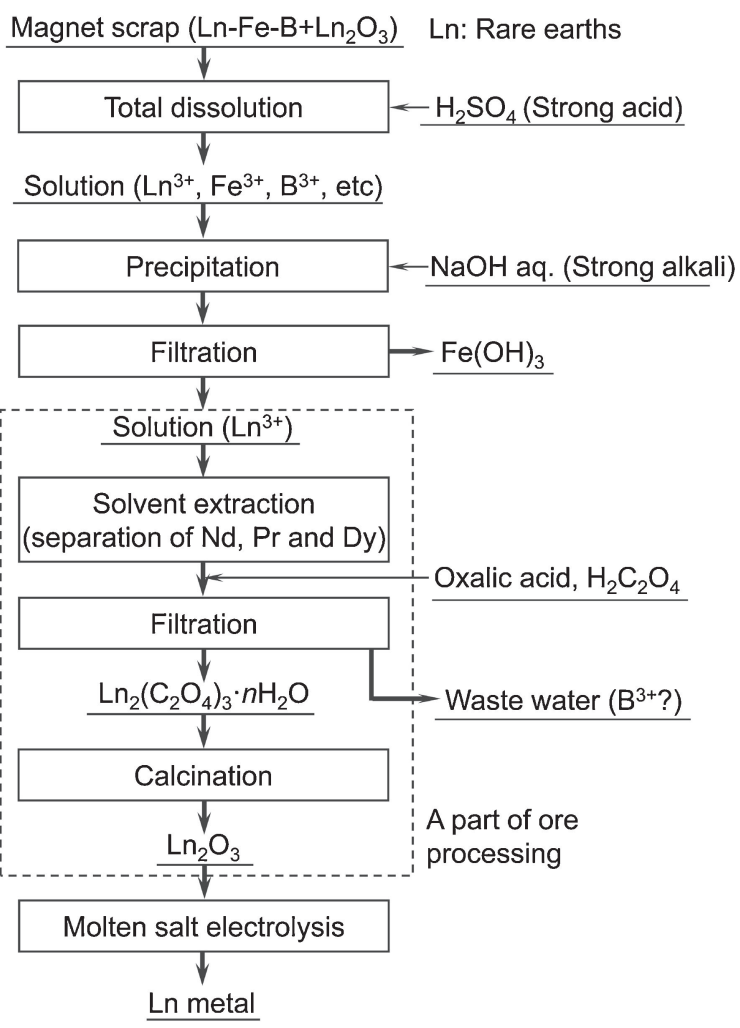

Fig. 1 Representative current recycling process for solid scrap generated in the production process of rare earth magnet. ${ }^{2}$ )

recycling is oxygen, and oxygen concentration in the alloy should be decreased. The magnet alloy waste is melted together with fluoride flux such as $\mathrm{LiF}-\mathrm{NdF}_{3}$ mixed salt. Rare earth oxide contained in the waste reacts with rare earth fluoride in the flux to be rare earth oxyfluoride. The oxyfluoride dissolves into the fluoride flux to be oxyfluoride ion. ${ }^{13)}$

$$
\mathrm{Nd}_{2} \mathrm{O}_{3}(\mathrm{~s})+\underline{2 \mathrm{NdF}_{3}} \text { (in flux) }=\underline{\mathrm{Nd}_{4} \mathrm{O}_{3} \mathrm{~F}_{6}} \text { (in flux) }
$$

Refined alloy is used as a master alloy for magnet production. Rare earth oxide extracted in the flux is converted into rare 


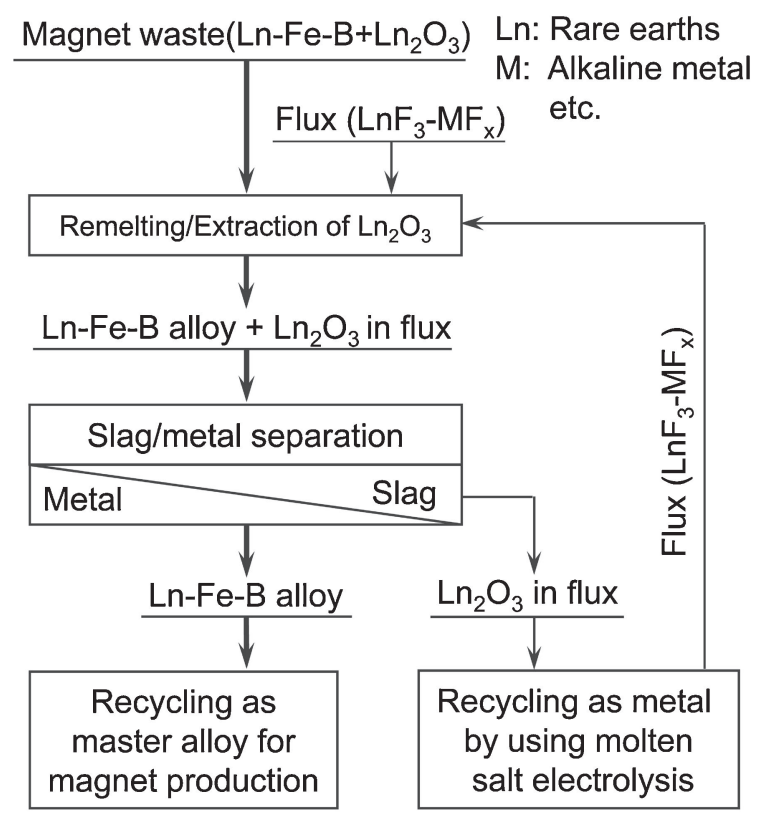

Fig. 2 Recycling process for the rare earth magnet waste by using molten fluoride under investigation.

earth metals by using molten salt electrolysis. The flux recovered after the electrolysis is returned to extraction process. The recycling process is highly feasible from the industrial point of view because (1) the reactor is very simple, (2) the liquid-liquid separation (molten fluoride/molten alloy) is suitable for massive treatment, (3) the energy consumption is low by recovering most alloy without oxidation, (4) no waste solution is generated.

The most important requirement for the flux is high solubility of rare earth oxide in molten fluoride in the extraction process. Therefore, the authors previously investigated the phase equilibria between molten fluoride and rare earth oxide. ${ }^{13)}$ As a result, solubility of $\mathrm{Nd}_{2} \mathrm{O}_{3}$ in $\mathrm{LiF}-$ $50 \mathrm{~mol}^{2} \mathrm{NdF}_{3}$ at $1473 \mathrm{~K}$ was estimated to be 7.4 mass $\%$. Solubility of $\mathrm{Dy}_{2} \mathrm{O}_{3}$ in $\mathrm{LiF}-50 \mathrm{~mol} \% \mathrm{DyF}_{3}$ at $1473 \mathrm{~K}$ was estimated to be 7.6 mass $\%$. Based on the investigation, the extraction of rare earth oxide using molten fluoride from actual magnet alloy waste is tried in this study.

Suitable remelting temperature is briefly discussed below. An intermetallic compound $\mathrm{Nd}_{2} \mathrm{Fe}_{14} \mathrm{~B}$, the matrix of the magnet alloy, decomposes to $\gamma$-Fe and liquid $\mathrm{Nd}-\mathrm{Fe}-\mathrm{B}$ phase at $1454 \mathrm{~K}\left(1181^{\circ} \mathrm{C}\right)$ by peritectic reaction. $\left.{ }^{14}\right)$ The fluidity of the alloy arises over the peritectic point, and rare earth oxide captured in the alloy is liberated. Therefore, the remelting temperature should be over the peritectic point. In this study, the remelting temperature was determined to be $1503 \mathrm{~K}$ from preliminary experiments. An iron crucible can be used in this process because a melt containing rare earth metals equilibrates with $\gamma$-Fe.

\section{Experimental}

\subsection{Sample preparation}

Off-specification magnet scrap with a nickel coating film was used as a magnet alloy waste. The nickel coating film was mechanically removed, and the scrap was crushed to

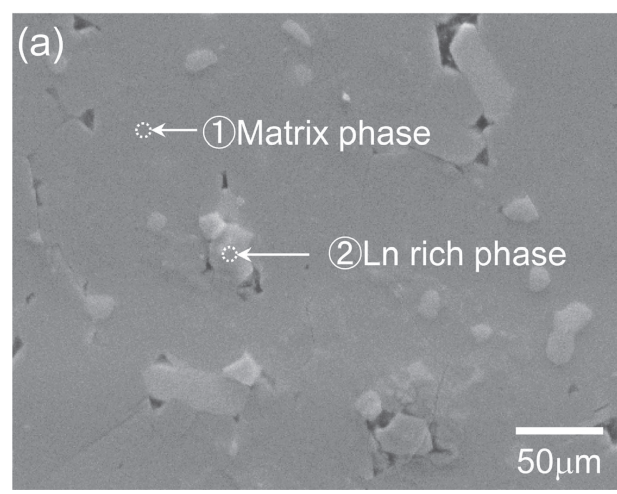

Composition (mass\%)

(1) Matrix phase:

Nd: 19, Pr: 3 ,

Dy: 9, Fe: 67

(2) Ln rich phase: Nd: 58 , Pr: 18 Dy: 8 , Fe: 9

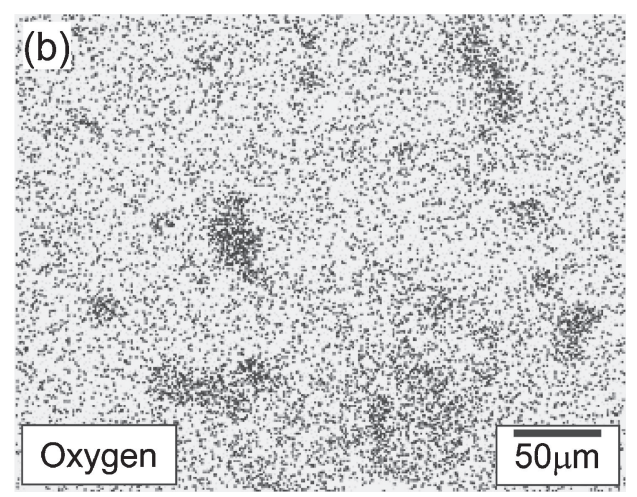

Fig. 3 (a) SEM image of cross section of the magnet alloy scrap used in this study. The results of the point analysis by using EDX are also shown. (b) EDX mapping of oxygen on the SEM image.

chips with 3-5 mm diameter. SEM image of cross section of the chip is shown in Fig. 3(a). An elemental mapping for oxygen by using EDX analyzer is also shown in Fig. 3(b). Dark matrix phase $\left(\mathrm{Ln}_{2} \mathrm{Fe}_{14} \mathrm{~B}, \mathrm{Ln}=\mathrm{Nd}, \mathrm{Pr}, \mathrm{Dy}\right)$ and light inclusion phase were observed on the SEM image. Oxygen and rare earths were concentrated in the inclusion. Therefore, the matrix should be decomposed in order to liberate the inclusion. In an experiment, $\mathrm{Fe}-24$ mass $\% \mathrm{Nd}$ (Fe-11 mol\% $\mathrm{Nd}$ ) alloy was prepared to be used as a simulated material of magnet alloy.

Lithium fluoride (LiF, 98\% purity), neodymium fluoride $\left(\mathrm{NdF}_{3}, 99.9 \%\right.$ purity) and dysprosium fluoride $\left(\mathrm{DyF}_{3}, 99.5 \%\right.$ purity) were used for preparing fluoride flux. The fluorides were mixed to compositions of $\mathrm{LiF}-50 \mathrm{~mol} \% \mathrm{NdF}_{3}$ and $\mathrm{LiF}-$ $25 \mathrm{~mol} \% \mathrm{NdF}_{3}-25 \mathrm{~mol} \% \mathrm{DyF}_{3}$. The mixed salt was charged into an iron crucible (99.8\% purity) and fused at $1473 \mathrm{~K}$ for $3 \mathrm{~h}$ under argon.

\subsection{Experimental procedure}

Experimental apparatus and conditions are shown in Fig. 4 and Table 1, respectively. The magnet alloy waste contained about 5000 mass-ppm oxygen ("mass-ppm" is abbreviated as "ppm" below). For instance, $1 \mathrm{~kg}$ of magnet alloy contains about $5 \mathrm{~g}$ of oxygen. If the oxygen exists as $\mathrm{Nd}_{2} \mathrm{O}_{3}, 35 \mathrm{~g}$ of $\mathrm{Nd}_{2} \mathrm{O}_{3}$ is contained in the alloy. About $470 \mathrm{~g}$ of fluoride flux is required for complete dissolution of $\mathrm{Nd}_{2} \mathrm{O}_{3}$ because solubility of $\mathrm{Nd}_{2} \mathrm{O}_{3}$ in $\mathrm{LiF}-50 \mathrm{~mol} \% \mathrm{NdF}_{3}$ at $1473 \mathrm{~K}$ is 7.4 mass \%. The amount of flux for complete dissolution is described as "equivalent amount" below. In experiment A and B series, flux of 0.5 and 1.5 times of equivalent amount were charged into the crucible, respectively. In experiment $\mathrm{C}$ 


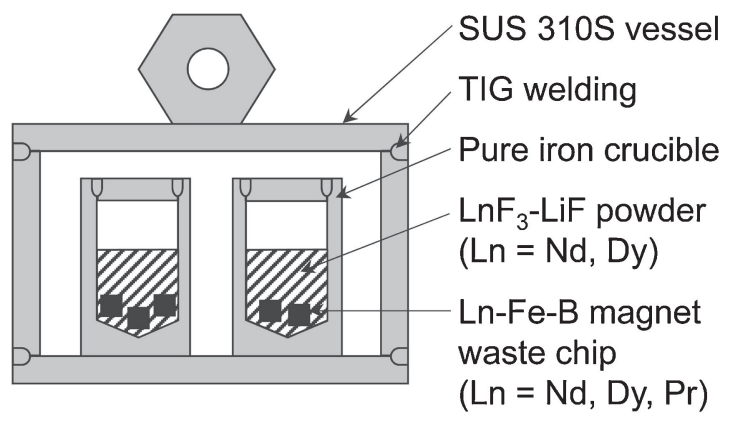

Fig. 4 Schematic illustration of the experimental apparatus for containing sample for the extraction experiment.

Table 1 Experimental conditions for extracting rare earth oxide from the magnet scrap by using molten fluoride at $1503 \mathrm{~K}$.

\begin{tabular}{|c|c|c|c|c|c|c|}
\hline \multirow{2}{*}{$\begin{array}{l}\text { Exp. } \\
\text { No. }\end{array}$} & \multirow{2}{*}{$\begin{array}{c}\text { Mass of } \\
\mathrm{Nd}-\mathrm{Fe}-\mathrm{B} \\
\text { magnet alloy, } \\
w_{\text {alloy }} / \mathrm{g}\end{array}$} & \multicolumn{3}{|c|}{ Composition of flux (mol\%) } & \multirow{2}{*}{$\begin{array}{c}\text { Mass of } \\
\text { flux, } \\
w_{\text {flux }} / \mathrm{g}\end{array}$} & \multirow{2}{*}{$\begin{array}{c}\text { Holding } \\
\text { time, } \\
t^{\prime \prime} / \mathrm{h}\end{array}$} \\
\hline & & $\mathrm{LiF}$ & $\mathrm{NdF}_{3}$ & $\mathrm{DyF}_{3}$ & & \\
\hline A-1 & 3.101 & 50 & 50 & 0 & 0.734 & 12 \\
\hline A-2 & 3.043 & 50 & 50 & 0 & 0.721 & 12 \\
\hline A-3 & 2.913 & 50 & 50 & 0 & 0.690 & 12 \\
\hline A-4 & 3.621 & 50 & 50 & 0 & 0.858 & 24 \\
\hline A-5 & 3.028 & 50 & 50 & 0 & 0.717 & 24 \\
\hline A-6 & 3.149 & 50 & 50 & 0 & 0.746 & 24 \\
\hline A-7 & 3.179 & 50 & 50 & 0 & 0.753 & 72 \\
\hline A-8 & 2.922 & 50 & 50 & 0 & 0.692 & 72 \\
\hline A-9 & 3.119 & 50 & 50 & 0 & 0.739 & 72 \\
\hline B-1 & 3.089 & 50 & 50 & 0 & 2.194 & 12 \\
\hline B-2 & 2.934 & 50 & 50 & 0 & 2.084 & 12 \\
\hline$B-3^{a}$ & 2.797 & 50 & 50 & 0 & 1.987 & 12 \\
\hline B-4 & 3.139 & 50 & 50 & 0 & 2.230 & 24 \\
\hline B-5 & 3.270 & 50 & 50 & 0 & 2.323 & 24 \\
\hline B- $6^{\mathrm{a}}$ & 2.701 & 50 & 50 & 0 & 1.918 & 24 \\
\hline B-7 & 3.234 & 50 & 50 & 0 & 2.297 & 72 \\
\hline B-8 & 3.084 & 50 & 50 & 0 & 2.191 & 72 \\
\hline B- $9^{\mathrm{a}}$ & 2.866 & 50 & 50 & 0 & 2.035 & 72 \\
\hline C-1 & 3.086 & 50 & 25 & 25 & 0.760 & 12 \\
\hline C-2 & 2.977 & 50 & 25 & 25 & 0.738 & 12 \\
\hline$C-3^{a}$ & 2.957 & 50 & 25 & 25 & 0.728 & 12 \\
\hline C-4 & 3.069 & 50 & 25 & 25 & 0.756 & 24 \\
\hline C-5 & 2.979 & 50 & 25 & 25 & 0.734 & 24 \\
\hline$C-6^{\mathrm{a}}$ & 2.648 & 50 & 25 & 25 & 0.651 & 24 \\
\hline C-7 & 3.020 & 50 & 25 & 25 & 0.744 & 72 \\
\hline C-8 & 2.814 & 50 & 25 & 25 & 0.693 & 72 \\
\hline$C-9^{a}$ & 2.846 & 50 & 25 & 25 & 0.701 & 72 \\
\hline
\end{tabular}

a: Subjected only to oxygen analysis.

series, flux of $\mathrm{LiF}-25 \mathrm{~mol} \% \mathrm{NdF}_{3}-25 \mathrm{~mol} \% \mathrm{DyF}_{3}$ was used. The flux was charged in the same ratio to experiment $\mathrm{A}$ series although the solubility of oxide in the flux is not known.

The magnet waste and fluoride flux were put into an iron crucible (99.7\% purity, $10 \mathrm{~mm}$ inner diameter, $10 \mathrm{~mm}$ depth) under argon to be sealed by TIG welding. The iron crucible was put into a stainless steel container (SUS 310S in JIS standard) to be sealed in the same manner. The stainless steel container was set in a vertical tube electric furnace under argon, and the sample was held at $1503 \mathrm{~K}\left(1230^{\circ} \mathrm{C}\right)$ for $43.2-$ $280.8 \mathrm{ks}(12-78 \mathrm{~h})$. The simulated alloy $(\mathrm{Fe}-24 \mathrm{mass} \% \mathrm{Nd}$ alloy) mentioned above was also used.

After the experiments, the stainless steel container was removed from the furnace and quenched in water. The iron crucible was mechanically recovered and was vertically cut into 2 pieces to be subjected to the analysis. One piece mounted in resin was polished by using emery papers and diamond pastes $(1 \mu \mathrm{m})$, coated by gold evaporation and analyzed by using a scanning electron microscopy and an energy dispersive X-ray analysis (SEM-EDX). Alloy and flux were recovered from another piece of iron crucible and analyzed by using a powder X-ray diffraction analysis (XRD) for phase determination, an inert gas fusion-infrared absorption method (TC-436, LECO Co.) for oxygen analysis, and an inductively coupled plasma-atomic emission spectroscopy (ICP-AES) for chemical analysis. In the oxygen analysis, sample (about $0.1 \mathrm{~g}$ ) recovered from 3 positions of the alloy was put into a nickel capsule $(0.5 \mathrm{~g})$ and burned in a graphite crucible. In the chemical analysis, samples (about $0.1 \mathrm{~g}$ ) were dissolved in a nitric acid to be subjected to analysis for neodymium, praseodymium, dysprosium, iron and boron.

\section{Results and Discussion}

\subsection{Separation of alloy and flux after remelting}

Photographs of cross section of iron crucible after the experiment are shown in Fig. 5. Abscissa shows holding time. Upper, middle and lower column shows Exps. A, B and $\mathrm{C}$, respectively. Alloy settled down and flux floated in all experiments. Interface between the alloy and flux was clear, and neither suspension of the alloy in flux nor suspension of the flux in alloy was observed in visual observation. Wettability between alloy and iron crucible was good. Namely, the alloy was finely separated from the flux.

SEM image of the interface between alloy and flux is shown in Fig. 6. The interface was clear even from the microscopic observation. Also no mutual suspension between the flux and alloy was observed even in the local analysis.

\subsection{Extraction and removal of oxide from magnet waste}

XRD patterns of flux after the experiments (held for $24 \mathrm{~h}$ ) are shown in Fig. 7. Neodymium oxyfluoride $\left(\mathrm{NdO}_{0.575} \mathrm{~F}_{1.85}\right.$ in JCPDS database) was identified in any flux. It was considered that $\mathrm{Nd}_{2} \mathrm{O}_{3}$ in magnet waste reacted with $\mathrm{NdF}_{3}$ in the flux to form the oxyfluoride. Namely, $\mathrm{Nd}_{2} \mathrm{O}_{3}$ in magnet waste was removed into the flux. In Exp. C (Fig. 7(c)), small peaks of $\mathrm{LiDyF}_{4}$ were found.

The oxyfluoride in the flux was also confirmed by using SEM-EDX (Fig. 6). Round phase of light gray color is the oxyfluoride in the figure. The size of the phase in Exp. B was smaller than that in Exp. A. This may be because oxyfluoride was dispersed by adding much flux.

Oxygen concentrations in the alloy (average of 3 positions in a piece) after the experiments are shown in Fig. 8. Extraction ratio of oxygen from magnet waste is also shown in right ordinate in the figure. In Exp. A, after 12 and $24 \mathrm{~h}$ 


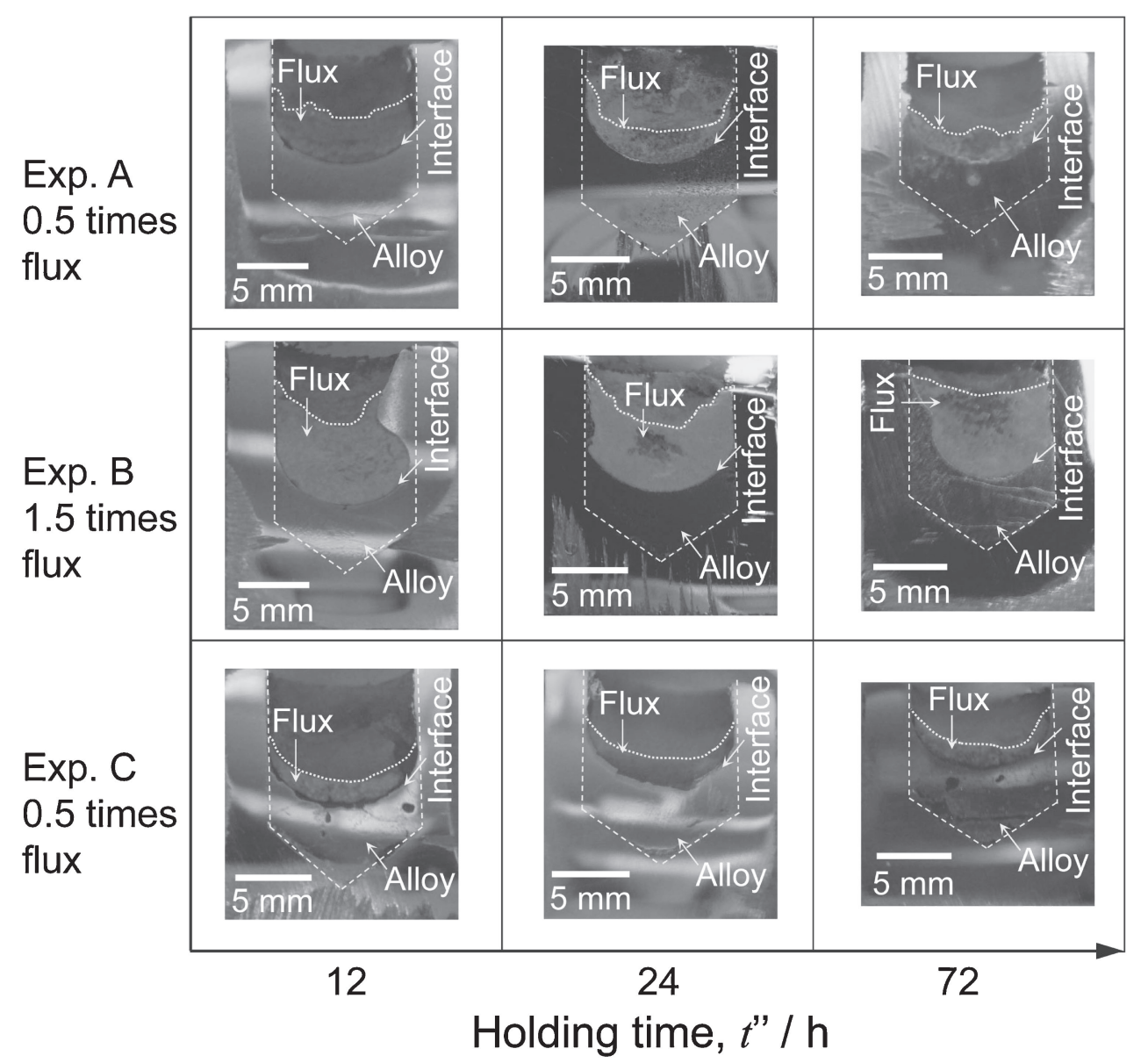

Fig. 5 Photographs of cross section of Fe crucible after the extraction experiments of rare earth oxide from the magnet alloy waste.

holding the oxygen concentration did not necessarily decrease. On the other hand, after $72 \mathrm{~h}$ holding the oxygen concentration decreased in any experiments, and minimum was $389 \mathrm{ppm}$ which meant the extraction ratio exceeded $80 \%$. Whole $\mathrm{Nd}_{2} \mathrm{O}_{3}$ is not dissolved into the flux under the condition in Exp. A. It was considered that the residual $\mathrm{Nd}_{2} \mathrm{O}_{3}$ reacted with $\mathrm{NdF}_{3}$ to form solid $\mathrm{Nd}_{4} \mathrm{O}_{3} \mathrm{~F}_{6}$ as a secondary phase in the flux. The oxyfluoride observed by XRD analysis and SEM analysis should form both in the extraction process at high temperature and in the solidification process by quench. In Exp. B, the concentration significantly decreased after $24 \mathrm{~h}$ holding in any experiments. Minimum concentration for $72 \mathrm{~h}$ holding was $160 \mathrm{ppm}$. The extraction ratio exceeded $90 \%$. In Exp. C, the decrease of oxygen concentration does not show significant tendency.

When pellets of neodymium oxyfluoride were immersed in molten fluoride in the previous study, the pellet incompletely dissolved into the fluoride even after $24 \mathrm{~h}$ holding. ${ }^{13)}$ Namely, it takes long time for complete dissolution of oxyfluoride under static condition. Hence, it might take long time to decrease oxygen concentration in the present experiments. The dissolution rate should be increased for practical application by employing an additional device to give strong agitation of the melts.

Residual oxygen concentration in the alloy in Exp. B was lower than that in Exp. A as described above. This difference may be because of less and more addition of fluoride than equivalent amount in Exp. A and Exp. B, respectively. In other words, it was estimated that oxyfluoride completely dissolved into molten fluoride and the activity of oxyfluoride decreased under unity (in the pure liquid standard state) in Exp. B.

Previous reports for deoxidation of neodymium metal are summarized in Table 2. ${ }^{15-20)}$ Mattocks et al. tried deoxidation of neodymium metal by using Solid State Electrotransport method (SSE). ${ }^{15)}$ High current (ex. $300 \mathrm{~A}$ ) was passed through a rod sample of $6 \mathrm{~mm}$ diameter under ultrahigh vacuum (ex. $4 \times 10^{-8} \mathrm{~Pa}$ ), and impurities were concentrated in one end in the method. ${ }^{21)} 45 \mathrm{ppm}$ oxygen decreased to $14 \mathrm{ppm}$ by the processing at $1113-1162 \mathrm{~K}$ for $789 \mathrm{~h}$. However, SSE is not suitable for the deoxidation of magnet waste because high energy is consumed and initial oxygen concentration of sample must be considerably low. Corbett et al. removed oxygen from neodymium metal by using neodymium chloride $\left(\mathrm{NdCl}_{3}\right)$ to form the oxychloride. $\left.{ }^{16}\right)$ $1599 \mathrm{ppm}$ oxygen deceased to $155 \mathrm{ppm}$ by the processing at $1063 \mathrm{~K}$ for $257 \mathrm{~h}$. The processing requires long time because the diffusion of oxygen in a solid sample requires long time under the melting point of neodymium $\left(1289 \mathrm{~K}^{22)}\right)$. Kamihira et al. tried the deoxidation by using calcium metal as a deoxidation agent. ${ }^{18)} 830 \mathrm{ppm}$ oxygen decreased to $205 \mathrm{ppm}$ by the processing in a calcia crucible at $1143 \mathrm{~K}$ for $18 \mathrm{~h}$. However, contamination by calcium is concerned in the method due to the direct contact of calcium with neodymium although the calcium concentration in neodymium after the deoxidation was not described in the report. Sano et al. 

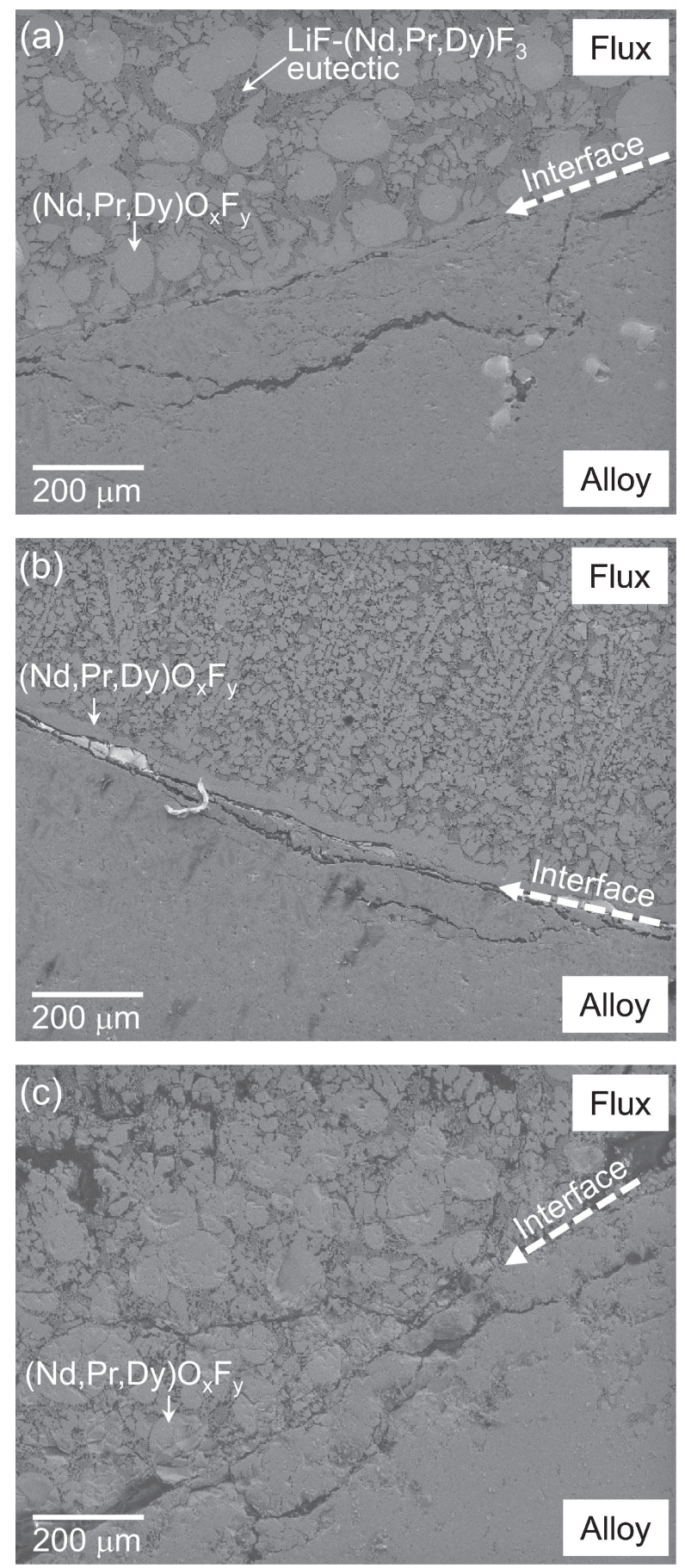

Fig. 6 SEM images of the boundary of the alloy and the flux after the experiments for $24 \mathrm{~h}$. (a) $\mathrm{LiF}-\mathrm{NdF}_{3}, 0.5$ times [Exp. A-4], (b) $\mathrm{LiF}-\mathrm{NdF}_{3}$, 1.5 times [Exp. B-4], (c) $\mathrm{LiF}-\mathrm{NdF}_{3}-\mathrm{DyF}_{3}, 0.5$ times [Exp. C-4].

removed oxygen by using the formation of oxyfluoride in the same manner to the present study. ${ }^{19)} 900 \mathrm{ppm}$ oxygen decreased to $200 \mathrm{ppm}$ by the processing at $1723 \mathrm{~K}$ for $3 \mathrm{~h}$. Neodymium is liquid at the holding temperature. Therefore, prompt deoxidation was realized because of fast transportation of oxygen. But operation temperature must be higher than melting point of $\mathrm{NdF}_{3}\left(1650 \mathrm{~K}^{22)}\right)$ by using pure $\mathrm{NdF}_{3}$ as the flux. Okabe et al. tried the deoxidation by polarizing neodymium cathodlically in molten calcium chloride (Electrochemical Deoxidation). ${ }^{20)}$ About $3.4 \mathrm{~V}$ was applied between neodymium cathode and graphite anode

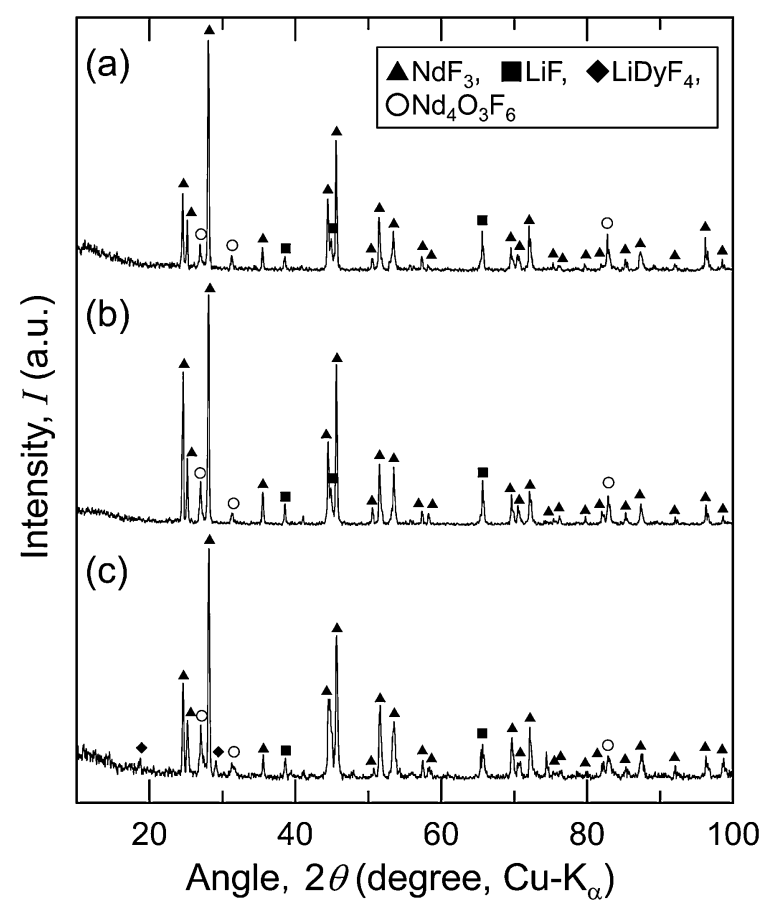

Fig. 7 X-ray diffraction patterns of the samples obtained after the experiments for $24 \mathrm{~h}$. (a) $\mathrm{LiF}-\mathrm{NdF}_{3}, 0.5$ times [Exp. A-4], (b) $\mathrm{LiF}-$ $\mathrm{NdF}_{3}, 1.5$ times [Exp. B-4], (c) $\mathrm{LiF}-\mathrm{NdF}_{3}-\mathrm{DyF}_{3}, 0.5$ times [Exp. C-4]. Reference pattern No. in JCPDS; $\mathrm{Nd}_{2} \mathrm{O}_{3}$ : 43-1023, $\mathrm{NdF}_{3}$ : 9-416, LiF: 4857, $\mathrm{LiDyF}_{4}:$ 27-1233, $\mathrm{Nd}_{4} \mathrm{O}_{3} \mathrm{~F}_{6}:$ 50-635.

at $1073 \mathrm{~K}$ for $10 \mathrm{~h}$, where current of about $2.0 \mathrm{~A}$ was passed. As a result, $1850 \mathrm{ppm}$ oxygen decreased to $20 \mathrm{ppm}$. But neodymium was contaminated by calcium whose concentration reached to 0.26 mass \%. Furthermore, it is unclear if magnet alloy wastes with diverse shape are homogeneously deoxidized or not.

In the present study, $5000 \mathrm{ppm}$ oxygen decreased to about $200 \mathrm{ppm}$ by the processing at $1530 \mathrm{~K}$ for $72 \mathrm{~h}$. The refined alloy is applicable for practical use because oxygen concentration is lower than that in a virgin neodymium of almost $500 \mathrm{ppm}$. Furthermore, the present process is suitable for massive treatment because the magnet alloy waste is molten.

\subsection{Substitution of rare earths between alloy and flux}

Rare earth content in the alloys after the experiment is shown in Fig. 9 which shows mole number of rare earths per $100 \mathrm{~g}$ of alloy (average of 2 to 3 experiments) against holding time. In Exp. A, neodymium increased, praseodymium decreased and dysprosium did not change. Increased amount of neodymium was almost same to decreased amount of praseodymium. It was considered that praseodymium in the alloy was substituted by neodymium in the flux. On the other hand, the contents of other elements such as iron and boron did not change after the experiment. In Exp. B, neodymium increased, praseodymium decreased and dysprosium did not change in the same manner to Exp. A. In Exp. C, neodymium and praseodymium decreased and dysprosium increased. It was considered that praseodymium and neodymium in the alloy were substituted by dysprosium in the flux because the contents of other elements did not change after the experiment. 
(a)

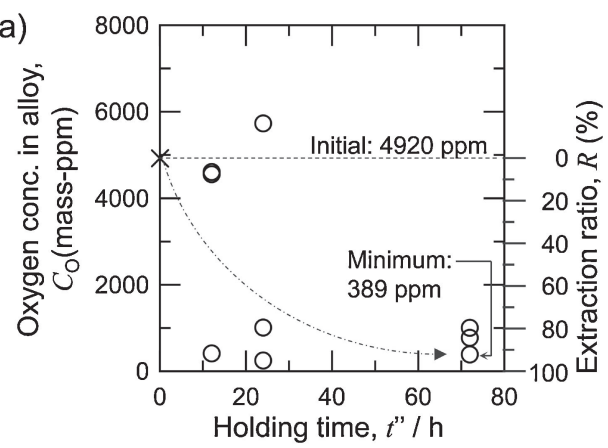

(b)

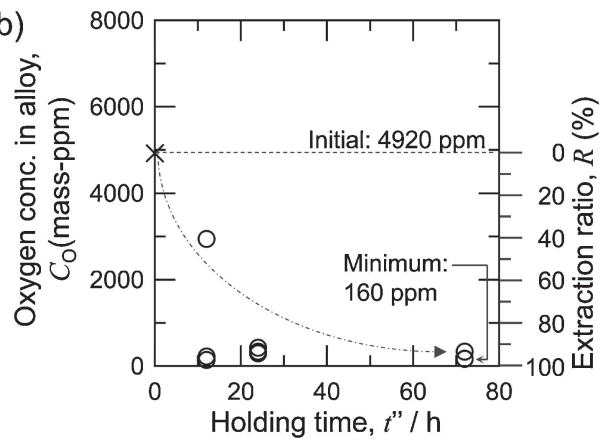

(c)

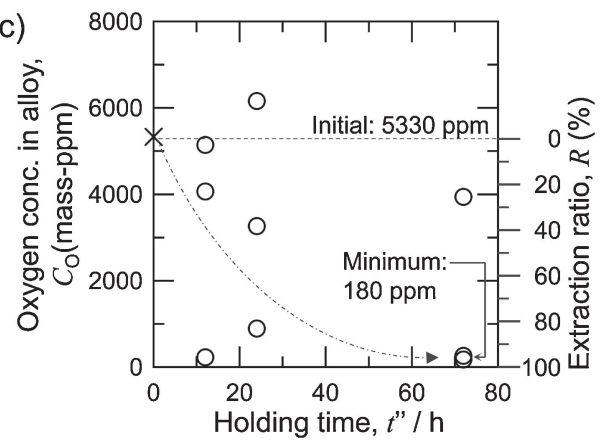

Fig. 8 Oxygen concentration of the obtained alloys determined by using infrared absorption method. (a) $\mathrm{LiF}-\mathrm{NdF}_{3}, 0.5$ times [Exp. A], (b) $\mathrm{LiF}-$ $\mathrm{NdF}_{3}, 1.5$ times [Exp. B], (c) $\mathrm{LiF}-\mathrm{NdF}_{3}-\mathrm{DyF}_{3}, 0.5$ times [Exp. C]. (a)

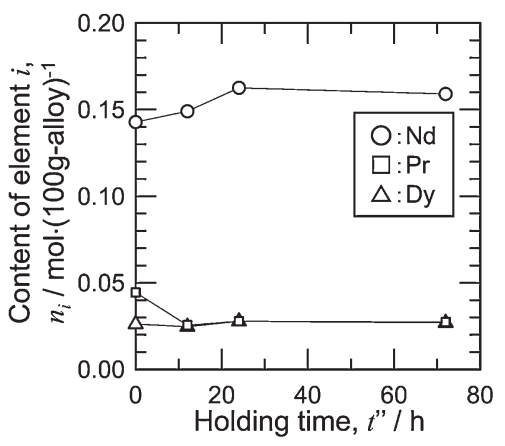

(b)

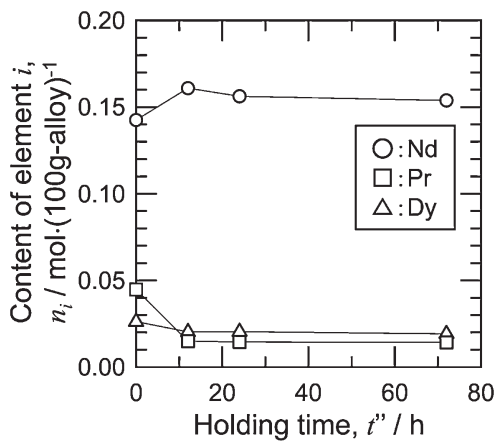

(c)

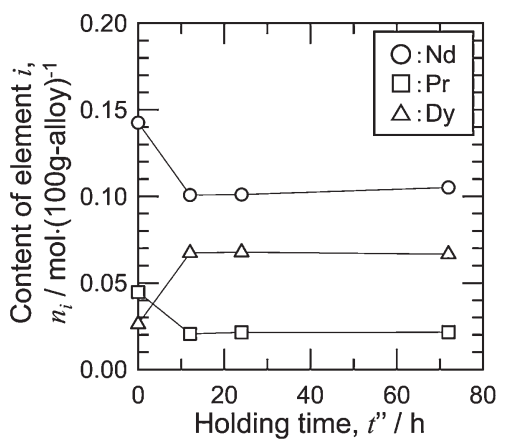

Fig. 9 Content of $\mathrm{Nd}$, Pr and Dy in the obtained alloy determined by using ICP-AES. (a) $\mathrm{LiF}-\mathrm{NdF}_{3}, 0.5$ times [Exp. A], (b) $\mathrm{LiF}_{-} \mathrm{NdF}_{3}, 1.5$ times [Exp. B], (c) $\mathrm{LiF}_{-} \mathrm{NdF}_{3}-\mathrm{DyF}_{3}, 0.5$ times [Exp. C]. Average of 2 to 3 experiments.

Table 2 Comparison of the result of deoxidation of magnet alloy in this study with that of Nd metal previously reported.

\begin{tabular}{|c|c|c|c|c|c|c|c|}
\hline \multirow{2}{*}{ Material } & \multirow{2}{*}{ Authors } & \multirow{2}{*}{ Method } & \multirow{2}{*}{$\begin{array}{c}\text { Temperature, } \\
T / \mathrm{K}\end{array}$} & \multirow{2}{*}{$\begin{array}{l}\text { Holding time, } \\
\qquad t^{\prime \prime} / \mathrm{h}\end{array}$} & \multicolumn{2}{|c|}{ Oxygen conc., $C_{\mathrm{O}}$ (mass-ppm) } & \multirow{2}{*}{ Reference } \\
\hline & & & & & Before exp. & After exp. & \\
\hline Nd metal & Mattocks et al. & $\mathrm{SSE}^{* 1}$ & $1113-1161$ & 789 & 45 & 14 & 15) \\
\hline Nd metal & Corbett et al. & Oxyhalide & 1063 & 257 & 1595 & 155 & 16) \\
\hline Nd metal & Fort et al. & $\mathrm{SSE}^{* 1}$ & $1093-1136$ & 500 & 40 & 20 & 17) \\
\hline Nd metal & Kamihira et al. & $\mathrm{Ca} / \mathrm{CaO}$ & 1143 & 18 & 830 & 205 & 18) \\
\hline Nd metal & Okabe et al. & Electro-deox ${ }^{* 2}$ & 1073 & 10 & 1850 & 20 & 20) \\
\hline $\mathrm{Nd}-\mathrm{Fe}-\mathrm{B}$ alloy & Takeda et al. & Oxyhalide & 1503 & 72 & 4920 & 160 & This study \\
\hline
\end{tabular}

${ }^{* 1}$ SSE denotes "Solid state electrotransport".

*2Electro-deox denotes "Electrochemical deoxidation".

SEM image of cross section of the alloy after the experiment is shown in Fig. 10. Compositions determined by point analysis of EDX are also shown in the figure. Matrix phase of iron-rare earth alloy, rare earth rich phase and almost pure iron phase were observed in any samples. But dysprosium concentrations in the matrix phase and rare earth rich phase in Exp. $\mathrm{C}$ were significantly higher than those in Exp. A and B. This result was well consistent with the result of ICP analysis.

The verification for the substitution of rare earths was carried out by using $\mathrm{Fe}-24$ mass $\% \mathrm{Nd}(\mathrm{Fe}-11 \mathrm{~mol} \% \mathrm{Nd}$ ) alloy and $\mathrm{DyF}_{3}$. Following reaction was thermodynamically expected. 

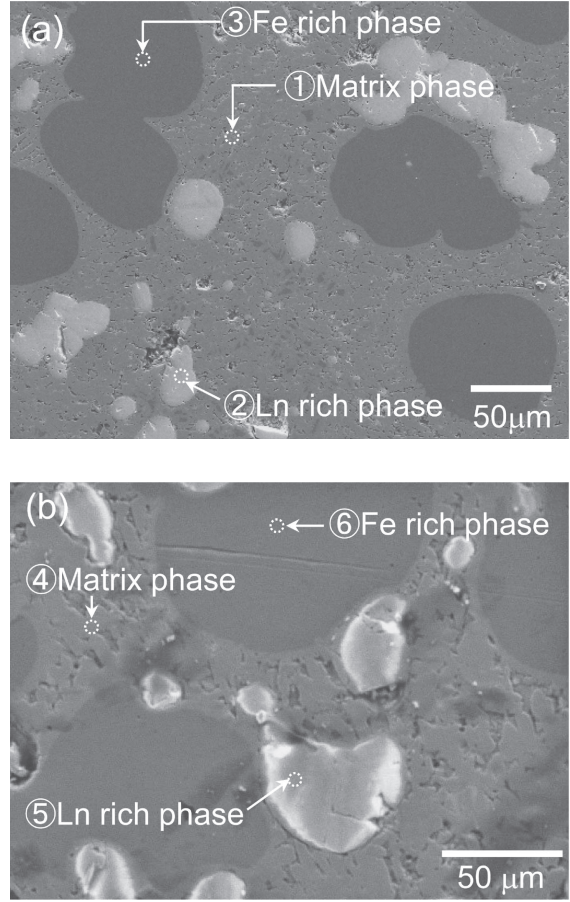

Composition (mass $\%$ )

(4) Matrix phase:

Nd: 22, Pr: 2,

Dy: 5, Fe: 70

(5) Ln rich phase: Nd: $78, \mathrm{Pr}: 8$, Dy: 3, Fe: 0.5

6)Fe rich phase Nd: 0.8, Pr: 0.7, Dy: 1, Fe: 97

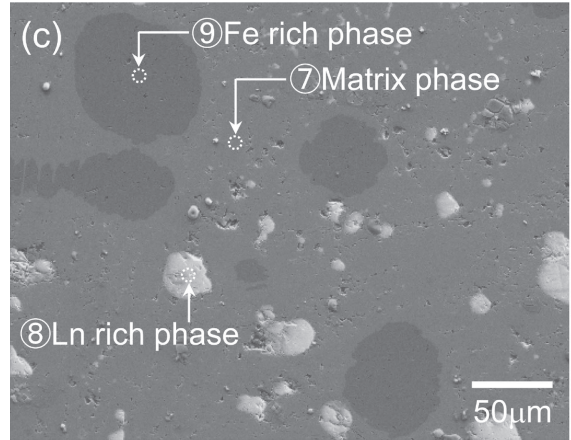

Composition (mass\%)

(7) Matrix phase:

Nd: 11, Pr: 3 ,

Dy: 12, Fe: 71

(8) Ln rich phase:

Nd: 56, Pr: 11,

Dy: 18 , Fe: 3

(9)Fe rich phase Nd: 0.3, Pr: 0.7, Dy: 0.8 , Fe: 97

Fig. 10 SEM images of the cross section of the alloy after the experiments for $24 \mathrm{~h}$. (a) $\mathrm{LiF}-\mathrm{NdF}_{3}, 0.5$ times [Exp. A-4], (b) $\mathrm{LiF}-\mathrm{NdF}_{3}, 0.5$ times [Exp. B-4], (c) $\mathrm{LiF}_{-} \mathrm{NdF}_{3}-\mathrm{DyF}_{3}, 0.5$ times [Exp. C-4]. The results of point analysis by using EDX are also shown.

$$
\begin{aligned}
& \underline{\mathrm{Nd}} \text { (in alloy) }+\underline{\mathrm{DyF}_{3}} \text { (in flux) } \\
& \quad=\underline{\mathrm{NdF}_{3}} \text { (in flux) }+\underline{\mathrm{Dy}} \text { (in alloy) } \\
& \Delta G_{(2)}=\Delta G_{(2)}^{\circ}+R T\left(\frac{a_{\mathrm{NdF}_{3}} a_{\mathrm{Dy}}}{a_{\mathrm{Nd}} a_{\mathrm{DyF}_{3}}}\right)
\end{aligned}
$$

Where $\Delta G_{(2)}$ is Gibbs energy change of reaction (2), $\Delta G_{(2)}^{\circ}$ is standard Gibbs energy change of reaction (2). $R$ is gas constant, $T$ is absolute temperature and $a_{i}$ is activity of component $i$.

$\Delta G_{(2)}^{\circ}$ is calculated to be $+17.2 \mathrm{~kJ} \cdot \mathrm{mol}^{-1}$ at $1573 \mathrm{~K}$ from a thermodynamic compilation. ${ }^{22}$ In the composition of $\mathrm{Fe}-11 \mathrm{~mol} \% \mathrm{Nd}, \mathrm{Fe}-\mathrm{Nd}$ solution equilibrates with $\gamma$-Fe at $1573 \mathrm{~K},{ }^{23)}$ and the $a_{\mathrm{Nd}}$ is estimated to be 0.19 (in the pure liquid standard state) from the extrapolation of the value measured by Nagai et al. ${ }^{24)}$ If all neodymium is substituted by dysprosium, Fe-11 mol\% Dy alloy is formed. In the composition, $\mathrm{Fe}_{17} \mathrm{Dy}_{2}$ intermetallic compound equilibrates with $\gamma-\mathrm{Fe}$ at $1573 \mathrm{~K},{ }^{25}$ ) and the $a_{\mathrm{Dy}}$ is 0.0092 (in the pure solid standard state) from the value measured by Nagai et al. ${ }^{26)} \Delta G_{(2)}$ is calculated to be $-22.4 \mathrm{~kJ} \cdot \mathrm{mol}^{-1}$ at $1573 \mathrm{~K}$
Table 3 Composition of alloy before and after the contact of $\mathrm{Fe}-\mathrm{Nd}$ alloy with molten $\mathrm{DyF}_{3}$ at $1573 \mathrm{~K}$ for $24 \mathrm{~h}$.

\begin{tabular}{cccc}
\hline & \multicolumn{4}{c}{ Concentration of element $i, C_{i}(\operatorname{mass} \%)^{*}$} \\
\cline { 2 - 4 } & $\mathrm{Fe}$ & $\mathrm{Nd}$ & $\mathrm{Dy}$ \\
\hline Before exp. & 75.6 & 24.4 & $<0.1$ \\
After exp. & 74.6 & 7.8 & 17.7 \\
\hline
\end{tabular}

*Determined by using ICP-AES.

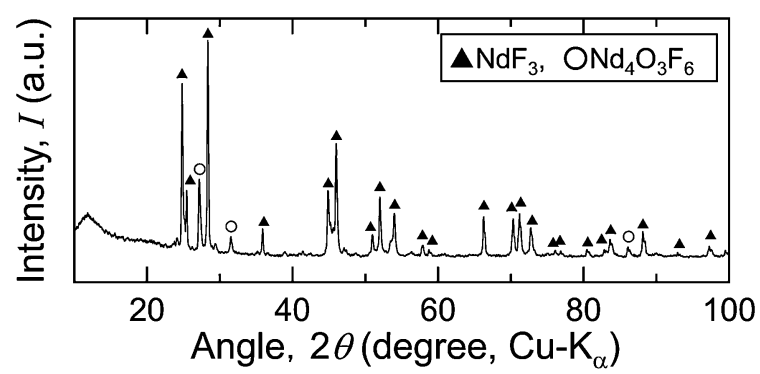

Fig. 11 X-ray diffraction patterns of the samples obtained after the contact of $\mathrm{Fe}-\mathrm{Nd}$ alloy with molten $\mathrm{DyF}_{3}$ at $1573 \mathrm{~K}$ for $24 \mathrm{~h}$. Reference pattern No. in JCPDS; $\mathrm{NdF}_{3}$ : 9-416, $\mathrm{Nd}_{4} \mathrm{O}_{3} \mathrm{~F}_{6}: 50-635$.

by assuming $a_{\mathrm{NdF}_{3}}=a_{\mathrm{DyF}_{3}}=1$. Namely, reaction proceeds to right-hand side.

In the verification experiment, the $\mathrm{Fe}-\mathrm{Nd}$ alloy was fused together with $\mathrm{DyF}_{3}$ (m.p. $1430 \mathrm{~K}$ ) and held at $1573 \mathrm{~K}$ for $24 \mathrm{~h}$. Composition of alloy and XRD pattern of flux after the reaction are shown in Table 3 and Fig. 11, respectively. Concentration of neodymium decreased from 24.4 to 7.8 mass $\%$, and concentration of dysprosium increased from $<0.1$ to 17.7 mass\%. Furthermore, $\mathrm{NdF}_{3}$ and $\mathrm{Nd}_{4} \mathrm{O}_{3} \mathrm{~F}_{6}$ were formed, and $\mathrm{DyF}_{3}$ disappeared. Namely, substitution of neodymium and dysprosium between alloy and flux occurred in the simplified system.

\subsection{Characteristic of the recycling process of this study}

Recycling processes previously investigated are classified to (a) extraction type: pure rare earth metals are regenerated by extracting rare earths from wastes, ${ }^{3-11)}$ and (b) refining type: alloys containing rare earth are regenerated by removing harmful elements from rare earth wastes. ${ }^{2,13)}$ The advantage and disadvantage of the processes are summarized in Table 4.

Extraction type recycling has advantages that pure rare earth metal is obtained since separation of rare earth elements is available and removal of heavily-concentrated impurities is possible. On the other hand, the recycling has disadvantages that long time and huge energy are required for processing, environmental burden is high and location for processing is limited.

Refining type recycling has disadvantage that precise control of composition of regenerated alloy is difficult when various wastes are mixed. On the other hand, the recycling has advantage that time for processing is short, energy consumption is small and location for processing is not limited.

There are various type of magnet wastes. Extraction type recycling is suitable for a heavily contaminated waste with 
Table 4 Comparison of recycling processes between extraction type and refining type.

\begin{tabular}{|c|c|c|}
\hline Classification & Advantage & Disadvantage \\
\hline Extraction type & $\begin{array}{l}\text { - Pure rare earth metal is obtained since } \\
\text { separation of rare earth elements is available. } \\
\text { - Removal of heavily-concentrated } \\
\text { impurities is possible. }\end{array}$ & $\begin{array}{l}\text { - Long time and huge energy are } \\
\text { required for processing. } \\
\text { - Environmental burden is high. } \\
\text { - Location for processing is limited. }\end{array}$ \\
\hline Refining type & $\begin{array}{l}\text { - Rare earth containing alloy is obtained. } \\
\text { - Time for processing is short and } \\
\text { energy requirement is small. } \\
\text { - Location for processing is not limited. }\end{array}$ & $\begin{array}{l}\text { - Precise control of composition of } \\
\text { regenerated alloy is difficult when } \\
\text { various wastes are mixed. }\end{array}$ \\
\hline
\end{tabular}

oxygen such as sludge generated in cutting process. On the other hand, refining type recycling is suitable for a mildly contaminated waste such as a used (end-of-life) magnet. The refining type recycling should be frequently utilized because the used magnets will be drastically generated in near future.

\section{Conclusions}

Removal of rare earth oxide from off-specification magnet scrap was investigated by remelting the scrap together with fluoride flux (LiF-50 mol\% $\mathrm{NdF}_{3}$ and $\mathrm{LiF}-25 \mathrm{~mol}_{\%} \mathrm{NdF}_{3}-$ $25 \mathrm{~mol}_{\%} \mathrm{DyF}_{3}$ ) at $1503 \mathrm{~K}$ for the development of refining type recycling process. As a result, separation between the magnet alloy and fluoride flux after remelting was fine, and neither suspension of alloy in flux nor suspension of flux in alloy was observed. Oxygen concentration of the alloy decreased from 5000 to $160 \mathrm{ppm}$ by charging the flux of 1.5 times of equivalent amount. Substitution of neodymium in the alloy and dysprosium in the flux was observed. The investigated process should be frequently utilized particularly for mildly contaminated wasted such as a used (end-of-life) magnet because time for processing is short, energy requirement is small and location for processing is not limited.

\section{Acknowledgement}

This work was financially supported by a Grant-in-Aid for Young Scientists (Start-up) from the Ministry of Education, Culture, Sports, Science and Technology (MEXT), Japan (Project ID No. 19860015) and by a Research Grant from Arai Science and Technology Foundation.

\section{REFERENCES}

1) M. Sagawa: Materia Japan 40 (2001) 943-946.

2) N. Ishigaki and A. Ohta: An Overview of Functions and Applications of Rare Earths, ed. by G. Adachi, (CMC Publishing, Tokyo, 2006) pp. 13-16.
3) K. Murase, K. Machida and G. Adachi: J. Alloy. Compd. 217 (1995) 218-225.

4) T. Uda, K. T. Jacob and M. Hirasawa: Science 289 (2000) 2326-2329.

5) T. Uda: Mater. Trans. 43 (2002) 55-62.

6) S. Shirayama and T. H. Okabe: Abstracts of the Mining and Materials Processing Institute of Japan (MMIJ) 2008 Spring Meeting II, Tokyo, (2008) pp. 69-70.

7) T. H. Okabe, O. Takeda, K. Fukuda and Y. Umetsu: Mater. Trans. 44 (2003) 798-801.

8) O. Takeda, T. H. Okabe and Y. Umetsu: J. Alloy. Compd. 379 (2004) $305-313$.

9) O. Takeda, T. H. Okabe and Y. Umetsu: J. Alloy. Compd. 392 (2005) 206-213.

10) O. Takeda, T. H. Okabe and Y. Umetsu: J. Alloy. Compd. 408-412 (2006) 387-390.

11) Y. Xu, L. S. Chumbley and F. C. Laabs: J. Mater. Res. 15 (2000) 22962304.

12) R. O. Suzuki, A. Saguchi, W. Takahashi, T. Yagura and K. Ono: Mater. Trans. 42 (2001) 2492-2498.

13) O. Takeda, K. Nakano and Y. Sato: J. Alloy. Compd., submitted.

14) B. Hallemans, P. Wollants and J. R. Roos: J. Phase Equilib. 16 (1995) 137-149.

15) P. G. Mattocks, C. M. Muirhead, D. W. Jones, B. J. Beadry and K. A. Gschneider, Jr.: J. Less-Common Metals 53 (1977) 253-263.

16) J. D. Corbett, J. D. Smith and E. Garcia: J. Less-Common Metals 115 (1986) 343-355.

17) D. Fort, B. J. Beaudry and K. A. Gschneider, Jr.: J. Less-Common Metals 134 (1987) 27-44.

18) K. Kamihira, R. Hasegawa and O. Ogawa: Mater. Trans. JIM 34 (1993) 243-247.

19) H. Sano, M. Tashiro, T. Fujisawa and C. Yamauchi: Mater. Trans. JIM 40 (1999) 263-267.

20) T. H. Okabe, K. Hirota, Y. Waseda and K. T. Jacob: Shigen-to-Sozai 114 (1998) 813-818.

21) D. Fort: J. Less-Common Metals 134 (1987) 45-65.

22) I. Barin: Thermochemical Data of Pure Substance, (VCH Verlagsgesellschaft, Germany, 1993).

23) M.-A. Van Ende and I. H. Jung: J. Alloy. Compd. 548 (2013) 133-154.

24) T. Nagai, S. Shirai and M. Maeda: Thermochim. Acta 516 (2011) 8-12.

25) B. Predel: Landolt-Bornstein: Numerical Data and Functional Relationships in Science and Technology, Group IV, Vol. 5, Phase Equilibria, Crystallographic and Thermodynamic Data of Binary Alloys, sub. Vol. E, ed. by O. Madelung, (Springer, 1995) pp. 2-3.

26) T. Nagai, S. Shirai and M. Maeda: J. Chem. Thermodyn. 65 (2013) $78-82$. 